Article

\title{
Theoretical Study on the Mechanism of Hydrogen Donation and Transfer for Hydrogen-Donor Solvents during Direct Coal Liquefaction
}

\author{
Haigang Hao ${ }^{1, \dagger}$, Tong Chang ${ }^{2,+}$, Linxia Cui ${ }^{1}$, Ruiqing Sun ${ }^{1}$ and Rui Gao ${ }^{1, *}$ \\ 1 College of Chemistry and Chemical Engineering, Inner Mongolia University, Hohhot 010021, China; \\ haohaigang@imu.edu.cn (H.H.); imucuilinxia@163.com (L.C.); imusunruiqin@163.com (R.S.) \\ 2 Department of Applied chemistry, Yuncheng University, Yuncheng 044000, China; changtongct@163.com \\ * Correspondence: gaorui@imu.edu.cn; Tel.: +86-0471-4995400 \\ + These authors contributed equally to this work.
}

Received: 15 November 2018; Accepted: 7 December 2018; Published: 10 December 2018

check for updates

\begin{abstract}
As a country that is poor in petroleum yet rich in coal, it is significant for China to develop direct coal liquefaction (DCL) technology to relieve the pressure from petroleum shortages to guarantee national energy security. To improve the efficiency of the direct coal liquefaction process, scientists and researchers have made great contributions to studying and developing highly efficient hydrogen donor (H-donor) solvents. Nevertheless, the details of hydrogen donation and the transfer pathways of H-donor solvents are still unclear. The present work examined hydrogen donation and transfer pathways using a model $\mathrm{H}$-donor solvent, tetralin, by density functional theory (DFT) calculation. The reaction condition and state of the solvent (gas or liquid) were considered, and the specific elementary reaction routes for hydrogen donation and transfer were calculated. In the DCL process, the dominant hydrogen donation mechanism was the concerted mechanism. The sequence of tetralin donating hydrogen atoms was $\alpha-\mathrm{H}\left(\mathrm{C}_{1}-\mathrm{H}\right)>\delta-\mathrm{H}\left(\mathrm{C}_{4}-\mathrm{H}\right)>\beta-\mathrm{H}\left(\mathrm{C}_{2}-\mathrm{H}\right)>$ $\gamma-\mathrm{H}\left(\mathrm{C}_{3}-\mathrm{H}\right)$. Compared to methyl, it was relatively hard for benzyl to obtain the first hydrogen atom from tetralin, while it was relatively easy to obtain the second and third hydrogen atoms from tetralin. Comparatively, it was easier for coal radicals to capture hydrogen atoms from the $\mathrm{H}$-donor solvent than to obtain hydrogen atoms from hydrogen gas.
\end{abstract}

Keywords: direct coal liquefaction; hydrogen donor solvent; hydrogen donation mechanism; hydrogen transfer mechanism; DFT calculation

\section{Introduction}

Direct coal liquefaction (DCL) transforms solid coal to liquid fuels and chemicals, which is a clean and efficient technology for coal utilization [1]. As China is poor in petroleum yet rich in coal, it is vital to develop direct coal liquefaction to relieve the pressure from petroleum shortages, which would help guarantee national energy security and the rapid development of the national economy [2].

Coal $(\mathrm{H} / \mathrm{C}$ atomic ratio $\approx 0.8)$ is converted to liquid fuels $(\mathrm{H} / \mathrm{C}$ atomic ratio $\approx 2)$ by adding external hydrogen atoms to free radicals derived from coal pyrolysis during the DCL process [3]. Hence, it is very important to provide sufficient hydrogen atoms to stabilize fragments for producing more liquid fuels and inhibiting coke formation in the DCL process [4]. There are two kinds of main hydrogen atom sources in DCL: hydrogen gas and hydrogen donor (H-donor) solvents [5-7].

Generally, hydrogen gas is supposed to be the main hydrogen atom source in DCL [8,9]. In order to produce more liquid fuels, DCL processes traditionally operate at high hydrogen partial pressure $(\geq 20 \mathrm{MPa})$. Under such a severe reaction condition, traditional DCL faces many challenges, such as 
facilities manufacturing, safe operating conditions, and operating cost [10]. Consequently, there is interest in decreasing the reaction pressure for the DCL process. However, the hydrogen donating ability of hydrogen gas would be decreased along with the decrease of hydrogen pressure.

To reduce this unfavorable effect, improving the hydrogen donating ability of H-donor solvents has attracted much attention. The significance of H-donor solvents for the DCL process was first realized in the 1920s [11]. Since then, scientists and researchers have made great contributions to studying and developing highly efficient $\mathrm{H}$-donor solvents.

The role of H-donor solvents can be summarized as follows [12-15]: (1) to be used as a coal transport carrier which is convenient for coal slurry pipeline transport and heat transfer; (2) to disperse and dissolve coal particles and free radicals during the DCL process; (3) to dissolve hydrogen gas and keep the hydrogen concentration in the solvent for coal hydrogenation; and (4) to donate or transfer hydrogen atoms to coal radicals to produce liquid fuels. Compared to the fourth role of $\mathrm{H}$-donor solvents, the first three roles are relatively easy to understand. The intrinsic mechanism of the fourth role- the reaction pathways of donating and transferring hydrogen atoms to free radicals-is still ambiguous. So far, two hydrogen donation mechanisms are broadly reported.

McMillen [16-18] claimed that H-donor solvents could promote the fracture of covalent bonds in the coal structure. H-donor solvents react with coal molecules, as displayed in Figure 1 [19]. However, this mechanism is still controversial. According to their experiments of model reactions, other researchers believe that the promotion effect of $\mathrm{H}$-donor solvents can be completely neglected [20].

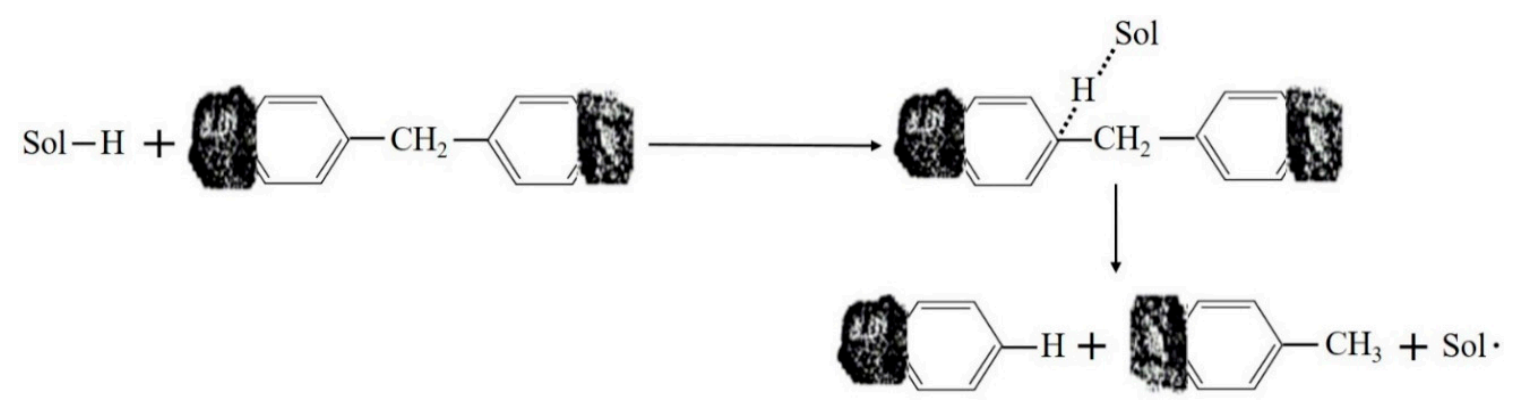

Figure 1. H-donor solvent engenders bond scission [19]. (Sol-H: H-Donor solvent; : coal).

Most scientists argue that $\mathrm{H}$-donor solvents react with free radicals derived from coal pyrolysis rather than coal molecules. This mechanism can be subdivided into two categories. The first is a stepwise mechanism, in which the hydrogen atoms of the H-donor are abstracted by external heat, forming hydrogen radicals, then reacting with free radicals produced from coal pyrolysis [21,22]. The other is a concerted mechanism, which suggests that free radicals react with the H-donor solvent, first forming a transition state, and then hydrogen atoms of the $\mathrm{H}$-donor solvent are transferred to free radicals [23].

So far, it is hard to analyze and characterize the real reactants and products of DCL, which has made it difficult to study this mechanism. Although many model compounds have been chosen to experimentally study the hydrogen donation pathways of H-donor solvents [24-26], the exact reaction routes are still debated. Density functional theory (DFT) provides a promising method to study the mechanism of this complex reaction [27].

Hou et al., using model compounds, compared the stepwise and concerted mechanisms and concluded that the concerted mechanism is more favorable than the stepwise mechanism [28]. However, they did not provide the detailed hydrogen donation pathways for model compounds of $\mathrm{H}$-donor solvents and did not consider the reaction condition.

The present work studied the hydrogen donation pathways using a model compound, tetralin, by DFT calculation. The reaction condition and state of solvent (gas or liquid) were considered. In this paper, the dominant mechanism between the stepwise and concerted mechanisms for tetralin as an 
H-donor solvent was identified. Further, the specific donation and transfer pathways were concluded for the dominant mechanism.

\section{Results}

Real industrial solvents are mixtures that consist of many substances (e.g., cyclic olefins, hydroaromatics, aromatics, cycloalkanes, etc.) [29]. Hence, scientists select model compounds, such as 4,5-dihydropyrene, 9,10-dihydroanthracene, 9,10-dihydrophenanthrene, or tetralin, to study the hydrogen donation mechanism of H-donor solvents $[23,28,30]$. Among these candidates, tetralin is the most popular due to its low cost, simple structure, and high performance.

In this study, tetralin was selected as the model compound to study hydrogen donation and transfer pathways. To clearly understand and describe the hydrogen donation pathways of tetralin, the 10 carbon atoms of tetralin are labeled as $C_{1}-C_{10}$ (see Figure 2).

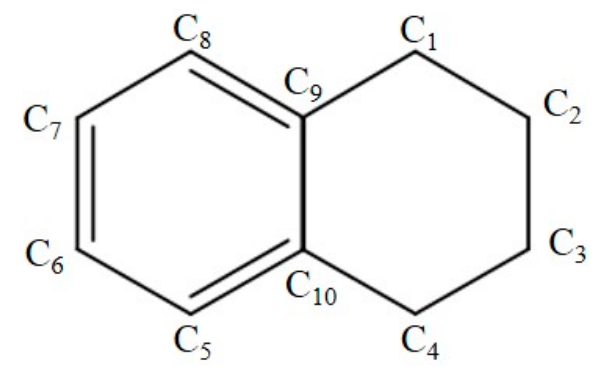

Figure 2. The naming rule for carbon atoms in tetralin for this study.

\subsection{Stepwise Mechanism}

For the stepwise mechanism, the $\mathrm{C}-\mathrm{H}$ bond of the $\mathrm{H}$-donor solvent fractures by thermal cracking, forming intermediates $(\mathrm{Sol} \bullet+\mathrm{H} \bullet)$. Then, the hydrogen radical $(\mathrm{H} \bullet)$ reacts with the coal radical $(\mathrm{R} \bullet)$, forming product $(\mathrm{R}-\mathrm{H})$, as mentioned before. In this case, the reaction barrier is effectively equal to the $\mathrm{C}-\mathrm{H}$ bond dissociation energy (BDE) of the $\mathrm{H}$-donor solvent.

It is believed that $\mathrm{C}_{1}-\mathrm{H}$ of tetralin would be donated first during the DCL process [28]. To better understand the stepwise mechanism, the influence of temperature and pressure on the BDE of the $\mathrm{C}_{1}-\mathrm{H}$ bond of tetralin, which has the highest possibility of donating a hydrogen atom, was further researched. As shown in Figure 3, pressure had little effect on the $\mathrm{C}_{1}-\mathrm{H} \mathrm{BDE}$ of tetralin, whereas the temperature had a significant impact on the $\mathrm{C}_{1}-\mathrm{H}$ BDE of tetralin. The $\mathrm{C}_{1}-\mathrm{H}$ BDE decreased from $305 \mathrm{~kJ} / \mathrm{mol}$ at $298 \mathrm{~K}$ to $245 \mathrm{~kJ} / \mathrm{mol}$ at $723 \mathrm{~K}$, which suggests that the possibility of donating a hydrogen atom to coal radicals increases as the temperature increases.

Under the DCL reaction condition at about $380-450{ }^{\circ} \mathrm{C}$, the possibility of donating a hydrogen atom from tetralin is very high. In order to understand the donation sequence of this H-donor solvent during the DCL process, the other BDEs of tetralin were also calculated. Although the majority of $\mathrm{H}$-donor solvents exist in the liquid state under real reaction conditions ( $20 \mathrm{MPa})$, there are still some $\mathrm{H}$-donor solvents that exist in the gas state in the reactor. In view of this possibility, the BDE of tetralin in gas and liquid states were both calculated, as shown in Table 1.

Table 1. The BDE (bond dissociation energies) energy of tetralin $(\mathrm{kJ} / \mathrm{mol})$.

\begin{tabular}{ccccccccccc}
\hline State & $\mathrm{C}_{6}=\mathrm{C}_{7}$ & $\mathrm{C}_{7}=\mathrm{C}_{\mathbf{8}}$ & $\mathrm{C}_{8}=\mathrm{C}_{\mathbf{9}}$ & $\mathrm{C}_{\mathbf{1}}-\mathrm{C}_{\mathbf{2}}$ & $\mathrm{C}_{\mathbf{1}}-\mathrm{C}_{\mathbf{9}}$ & $\mathrm{C}_{\mathbf{2}}-\mathrm{C}_{\mathbf{3}}$ & $\mathrm{C}_{\mathbf{1}}-\mathrm{H}$ & $\mathrm{C}_{\mathbf{2}}-\mathrm{H}$ & $\mathrm{C}_{\mathbf{8}}-\mathrm{H}$ & $\mathrm{C}_{\mathbf{7}}-\mathrm{H}$ \\
\hline Gas & 570.4 & 587.1 & 571.2 & 267.3 & 377.4 & 318.6 & 303.2 & 361.3 & 418.2 & 428.0 \\
Liquid & 569.5 & 585.2 & 569.3 & 266.7 & 377.0 & 318.0 & 304.3 & 361.0 & 422.7 & 427.4 \\
\hline
\end{tabular}

Comparatively, there are few differences for BDEs of tetralin between the gas and liquid states. Therefore, the existing state of the H-donor solvent would not affect its performance. As displayed in 
Table 1 , the BDE of the $\mathrm{C}_{1}-\mathrm{C}_{2}$ bond of tetralin was the smallest $(266.7 \mathrm{~kJ} / \mathrm{mol})$, followed by the $\mathrm{C}_{1}-\mathrm{H}$ bond of tetralin $(304.3 \mathrm{~kJ} / \mathrm{mol})$.

Scientists have researched the relationship between pyrolysis temperature and BDE, which is displayed in Table 2 [31]. According to Table 2, the covalent bonds of tetralin with BDEs between 210 and $320 \mathrm{~kJ} / \mathrm{mol}$ have the possibility of being thermally cracked under the reaction temperature (about $380-450^{\circ} \mathrm{C}$ ). If the carbon skeleton of tetralin is not destroyed under the reaction temperature, $\mathrm{C}_{1}-\mathrm{H}(304.3 \mathrm{~kJ} / \mathrm{mol})$ has the highest possibility of donating its hydrogen atom via the stepwise mechanism. Keeping the structure intact is very important for an $\mathrm{H}$-donor solvent under the DCL reaction temperature. Consequently, considerable efforts have been made to moderate the reaction conditions by decreasing the temperature and pressure.

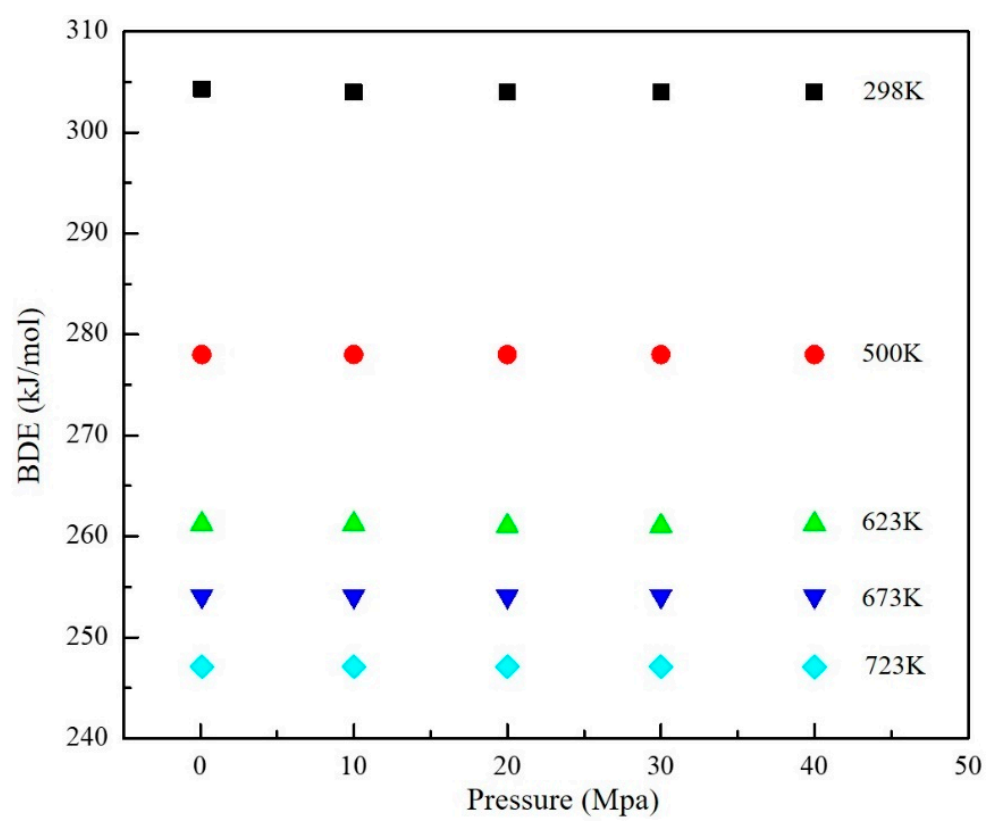

Figure 3. Effect of temperature and pressure on the dissociation energy of $\mathrm{C}_{1}-\mathrm{H}$ of tetralin.

Table 2. Correspondence between BED and temperature of homolytic cleavage. $\left(\mathrm{C}_{\mathrm{al}}\right.$ : aliphatic carbon, $\mathrm{C}_{\mathrm{ar}}$ : aromatic carbon) [31].

\begin{tabular}{clcc}
\hline & Chemical Bond Type & BDE (kJ/mol) & $\begin{array}{c}\text { Temperature of Bond } \\
\text { Cleavage }\left({ }^{\circ} \mathbf{C}\right)\end{array}$ \\
\hline $\mathbf{1}$ & Release of bonded water and decomposition of carboxylic acid & $<150$ & $<300$ \\
$\mathbf{2}$ & Breakage of bonds between $\mathrm{C}_{\mathrm{al}}$ and $\mathrm{O}, \mathrm{S}$, and N, and S-S & $150-230$ & $300-400$ \\
$\mathbf{3}$ & Breakage of bonds between $\mathrm{C}_{\mathrm{al}}$ and $\mathrm{C}_{\mathrm{al}}, \mathrm{H}, \mathrm{O}$, and Car-N & $210-320$ & $400-500$ \\
$\mathbf{4}$ & Breakage of bonds between $\mathrm{C}_{\mathrm{al}}$ and $\mathrm{C}_{\mathrm{al}}$ and $\mathrm{O}$ and $\mathrm{S}$ & $300-430$ & $500-600$ \\
$\mathbf{5}$ & Decomposition of carbonate in coals to generate $\mathrm{CO}_{2}$ & - & $\sim 700$ \\
$\mathbf{6}$ & Condensation of aromatics rings to release $\mathrm{H}_{2}$ & $>400$ & $740-800$ \\
\hline
\end{tabular}

In general, temperature has a significant effect on the BDE of tetralin, while the pressure and existing state of the $\mathrm{H}$-donor solvent would not affect its $\mathrm{BDE}$. $\mathrm{C}_{1}-\mathrm{H}$ of tetralin would be donated first during the DCL process via the stepwise mechanism. The possibility of donating a hydrogen atom from tetralin to radicals increases as the temperature increases. 


\subsection{Concerted Mechanisms}

Comparatively, if the reaction proceeds in a concerted manner, the $\mathrm{H}$-donor solvent breaks its $\mathrm{C}-\mathrm{H}$ bond through a transition state assisted by coal radicals. In this section, for studying the concerted mechanisms, two model radicals, methyl and benzyl, were chosen to represent the free radicals that derived from coal pyrolysis. The methyl radical represents the gas products and benzyl represents the liquid products.

The energy barrier of radicals reacted with tetralin, as displayed in Figure 4 . The barriers of reaction for methyl radicals with hydrogen atoms of tetralin are ranked in the following order $-\mathrm{C}_{7}-\mathrm{H}$ $>\mathrm{C}_{8}-\mathrm{H}>\mathrm{C}_{2}-\mathrm{H}>\mathrm{C}_{1}-\mathrm{H}-$ while the benzyl radicals are ranked in this order $-\mathrm{C}_{8}-\mathrm{H}>\mathrm{C}_{7}-\mathrm{H}>\mathrm{C}_{2}-\mathrm{H}$ $>\mathrm{C}_{1}-\mathrm{H}$. The reason for the different sequence of $\mathrm{C}_{7}-\mathrm{H}$ and $\mathrm{C}_{8}-\mathrm{H}$ for different radicals is the steric hindrance. For $\mathrm{C}_{1}-\mathrm{H}$ and $\mathrm{C}_{2}-\mathrm{H}$, the reaction barriers of methyl with tetralin were lower than that of benzyl, and the reaction energies of methyl with tetralin were larger than that of benzyl, indicating that small radicals were prone to be stabilized by a hydrogen atom donated from tetralin via the concerted mechanism both kinetically and thermodynamically.

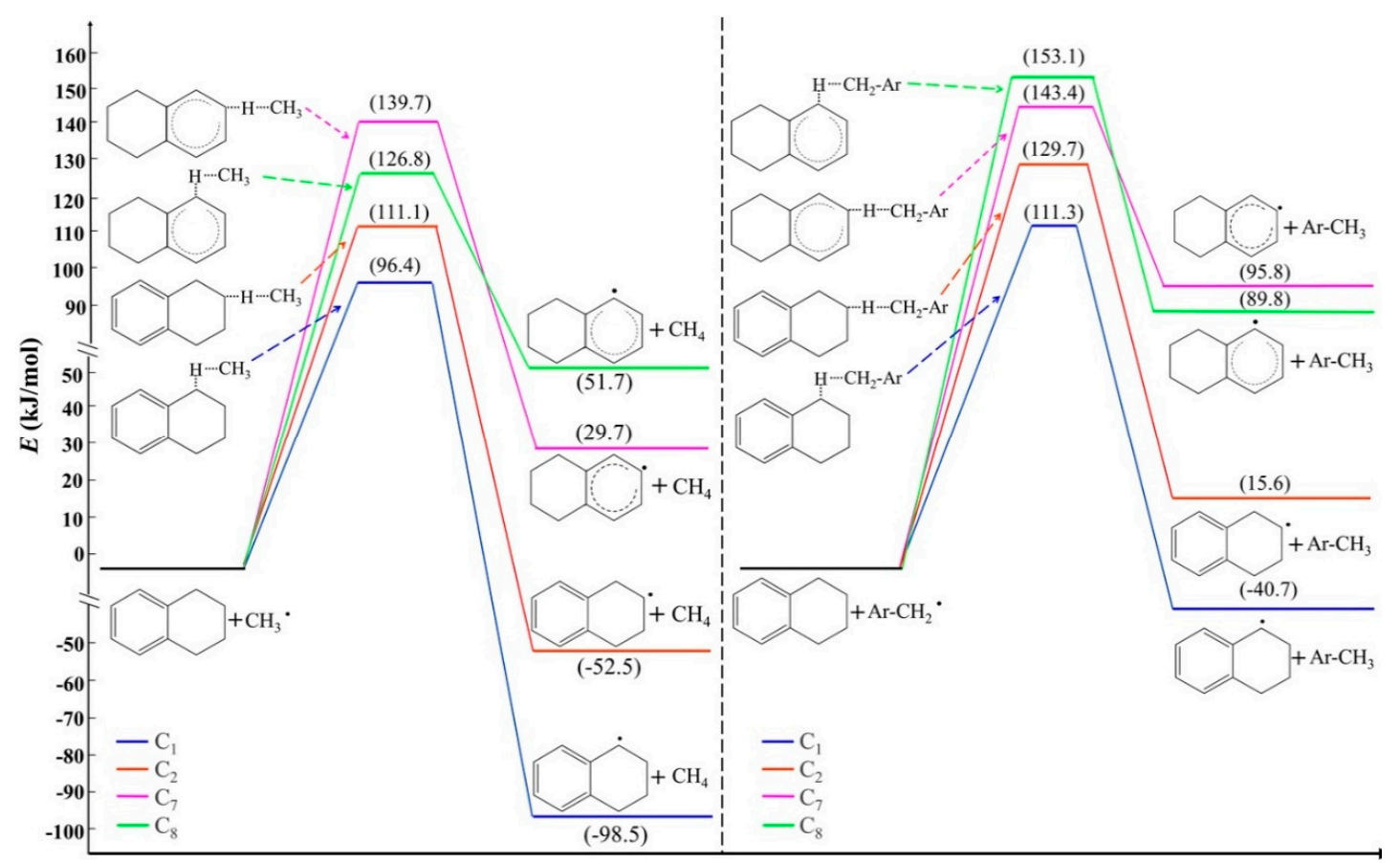

Figure 4. The energy barriers of radicals reacted with tetralin.

The comparison of two mechanisms is shown in Figure 5 and indicates that the concerted mechanism was favorable. This result agrees with the conclusion of the work reported by Hot et al. [28]. Comparatively, the calculated BDE of $\mathrm{C}_{1}-\mathrm{H}(\alpha-\mathrm{H})$ was smaller than that calculated by Hou et al. ( $250.5 \mathrm{vs} .357 .3 \mathrm{~kJ} / \mathrm{mol}$ ), while the calculated reaction barrier of $\mathrm{C}_{1}-\mathrm{H}$ with benzyl was bigger than that calculated by Hou et al. (111.3 vs. $62.8 \mathrm{~kJ} / \mathrm{mol})$. The reason for this difference is that our calculation considered the reaction condition and solvent effect, while Hot et al. only made calculations under standard conditions. This result indicates that if the carbon skeleton of tetralin were not destroyed under the reaction temperature, although the concerted mechanism is dominant, the possibility of the stepwise mechanism increases as the temperature increases. 


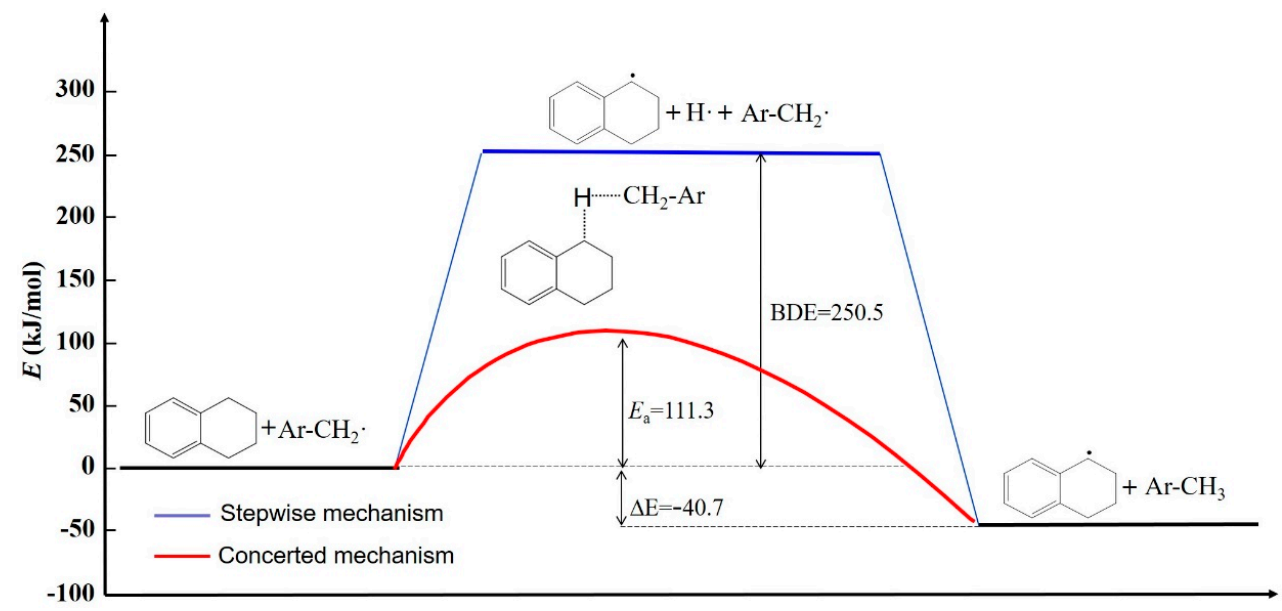

Figure 5. The comparison of the two mechanisms.

\subsection{Donation and Transfer Pathways}

When tetralin donates its first hydrogen atom and becomes a tetralyl, then there are two reaction routes that could happen: (1) tetralyl further donates its remaining hydrogen atoms to free radicals; or (2) tetralyl, as a new free radical, captures hydrogen atoms from other hydrogen-rich substances. These two reaction routes were studied using model radicals.

Comparatively, for the first route, the barriers of tetralyl donating a hydrogen atom to methyl and benzyl radicals were in the same order, $\mathrm{C}_{4}<\mathrm{C}_{2}<\mathrm{C}_{3}$, as shown in Figure 6 . If tetralyl donates the hydrogen atom $\mathrm{C}_{4}-\mathrm{H}$ or $\mathrm{C}_{2}-\mathrm{H}$ to free radicals, tetralyl would become a stable structure. However, if tetralyl donates the hydrogen atom $\mathrm{C}_{3}-\mathrm{H}$ to free radicals, tetralyl would become an unstable structure. Therefore, the reaction barrier of donating $\mathrm{C}_{3}-\mathrm{H}$ is the highest. Due to the steric hindrance, all the reaction barriers for the benzyl radical are higher than those for methyl. After donating the first hydrogen atom, $\mathrm{C}_{1}-\mathrm{H}, \mathrm{C}_{4}-\mathrm{H}$ of tetralin has the highest possibility to be donated.

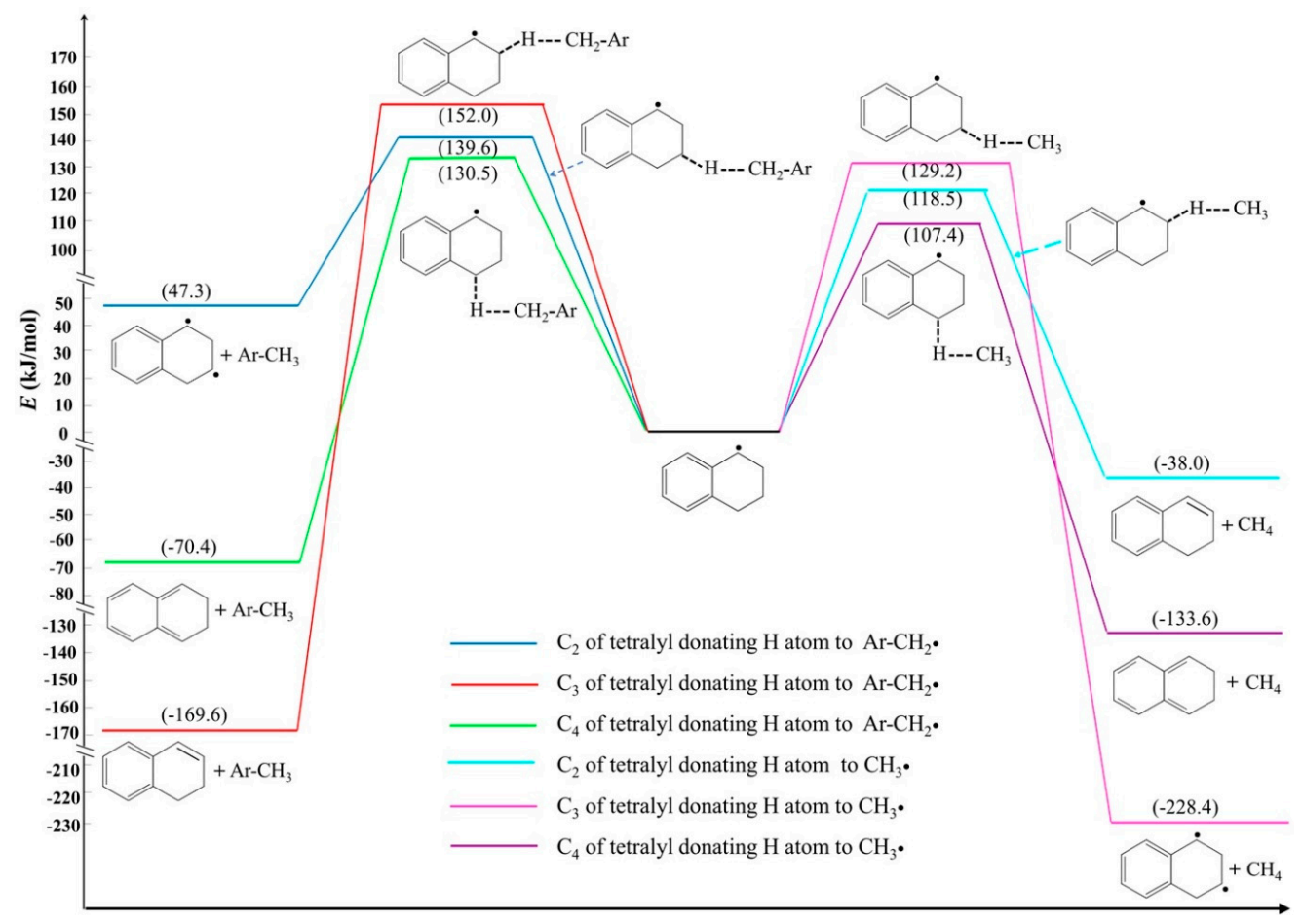

Figure 6. The barrier of tetralyl donating its hydrogen atoms. 
For the second route, two kinds of substances (tetralin and hydrogen) were selected as hydrogen-rich sources to study in this work. Comparatively, the barrier of tetralyl donating a hydrogen atom to benzyl and the barrier of tetralyl capturing a hydrogen atom from other hydrogen-rich sources are displayed in Figure 7. It can be clearly seen that it was hard to capture a hydrogen atom from hydrogen gas $(168.3 \mathrm{~kJ} / \mathrm{mol})$, however it was relatively easy to obtain a hydrogen atom from another tetralin kinetically $(131.8 \mathrm{~kJ} / \mathrm{mol})$. The reaction barrier of tetralyl donating the $\mathrm{C}_{4}-\mathrm{H}$ was smaller than the reaction barrier of tetralyl capturing a hydrogen atom from $\mathrm{H}_{2}(130.5 \mathrm{vs} .168 .3 \mathrm{~kJ} / \mathrm{mol})$, while it was almost equal to the reaction barrier of tetralyl obtaining a hydrogen atom from another tetralin ( $130.5 \mathrm{vs} .131 .8 \mathrm{~kJ} / \mathrm{mol}$ ). This suggests that tetralyl was prone to donate hydrogen atoms to radicals rather than transfer a hydrogen atom to radicals from hydrogen gas as a vehicle under DCL conditions.

Generally, this result contradicts the consensus of hydrogen gas being the main hydrogen atom resource of DCL other than the H-donor solvent. The reason for this contradiction may be the catalyst, which plays a very significant role in decomposing hydrogen gas in the DCL process. Hence, a preliminary study for tetralyl receiving a hydrogen atom from hydrogen gas with the aid of a catalyst should be performed in future.

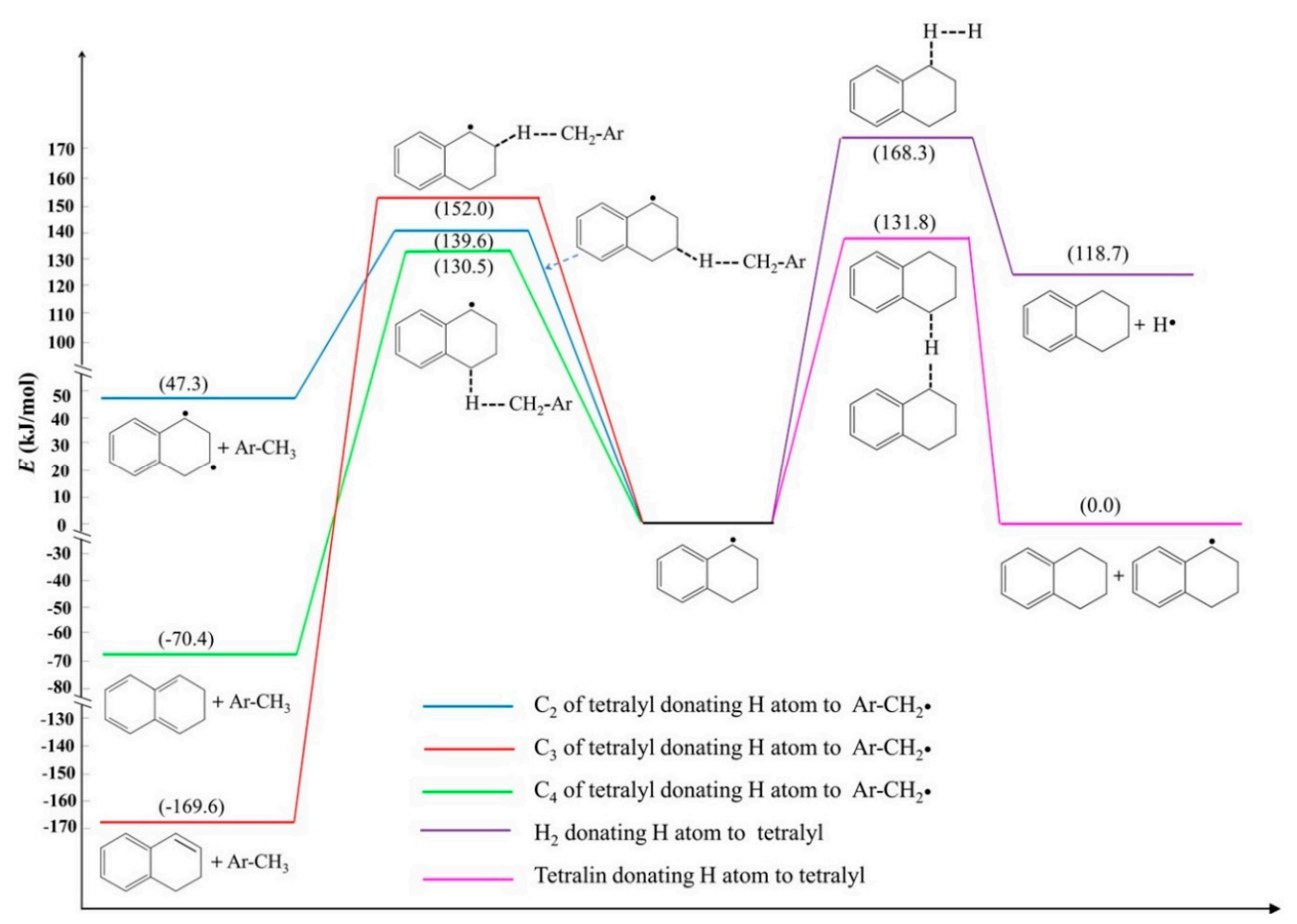

Figure 7. The comparison of barriers of tetralyl donating and transferring hydrogen atoms.

The sequence of donation of tetralin hydrogen atoms was $\mathrm{C}_{1}-\mathrm{H}>\mathrm{C}_{4}-\mathrm{H}>\mathrm{C}_{2}-\mathrm{H}>\mathrm{C}_{3}-\mathrm{H}$. Due to $\mathrm{C}_{1}-\mathrm{H}$ being equal to $\mathrm{C}_{4}-\mathrm{H}, \mathrm{C}_{2}-\mathrm{H}$ which was equal to $\mathrm{C}_{3}-\mathrm{H}$, the sequence of donation of tetralin hydrogen atoms also could be $\mathrm{C}_{4}-\mathrm{H}>\mathrm{C}_{1}-\mathrm{H}>\mathrm{C}_{3}-\mathrm{H}>\mathrm{C}_{2}-\mathrm{H}$. Table 3 shows the four reaction barriers of tetralin donating hydrogen atoms to radicals in sequence and the barriers of radicals obtaining hydrogen atoms from hydrogen gas without the aid of a catalyst. It suggests that it was relatively hard for benzyl to obtain the first hydrogen atom from tetralin, while it was relatively easy to obtain the second and the third hydrogen atoms from tetralin. The difference between two barriers donating the fourth hydrogen atoms of tetralin to methyl and benzyl was small. When tetralin donated two hydrogen atoms, it became 2,3-dihydronaphthalene. The reaction barriers of methyl that reacted with 2,3-dihydronaphthalene were much higher than those of benzyl, which reacted with 2,3-dihydronaphthalene (192.2 vs. $104.6 \mathrm{~kJ} / \mathrm{mol})$. While the reaction barriers of methyl reacted with 
$\mathrm{H}_{2}$, they were much lower than those of benzyl reacting with $\mathrm{H}_{2}(107.4 \mathrm{vs} .142 .9 \mathrm{~kJ} / \mathrm{mol})$. Compared to the reaction of radicals that reacted with $\mathrm{H}_{2}$, methyl radicals could obtain two hydrogen atoms from tetralin at most, while benzyl radicals were prone to capture all four hydrogen atoms from tetralin. The majority of coal radicals were bigger than benzyl, which suggests that it is easier for coal radicals to capture hydrogen atoms from $\mathrm{H}$-donor solvents than for coal radicals to obtain hydrogen atoms from hydrogen gas.

Table 3. The reaction barriers of model radicals capturing hydrogen atoms from tetralin and $\mathrm{H}_{2}$ $(\mathrm{kJ} / \mathrm{mol})$.

\begin{tabular}{|c|c|c|c|c|c|}
\hline \multirow[b]{2}{*}{ Model Compound } & \multicolumn{4}{|c|}{ Tetralin } & \multirow[b]{2}{*}{$\mathbf{H}_{2}$} \\
\hline & $\begin{array}{c}\mathrm{C}_{1}-\mathrm{H} \\
\text { (or } \mathrm{C}_{4}-\mathrm{H} \text { ) }\end{array}$ & $\begin{array}{c}\mathrm{C}_{4}-\mathrm{H} \\
\text { (or } \mathrm{C}_{1}-\mathrm{H} \text { ) }\end{array}$ & $\begin{array}{c}\mathrm{C}_{2}-\mathrm{H} \\
\text { (or } \mathrm{C}_{3}-\mathrm{H} \text { ) }\end{array}$ & $\begin{array}{c}\mathrm{C}_{3}-\mathrm{H} \\
\left.\text { (or } \mathrm{C}_{2}-\mathrm{H}\right)\end{array}$ & \\
\hline $\mathrm{CH}_{3} \bullet$ & 96.4 & 99.8 & 192.2 & 125.0 & 107.4 \\
\hline $\mathrm{Ar}-\mathrm{CH}_{2} \bullet$ & 111.3 & 72.7 & 104.6 & 129.8 & 142.9 \\
\hline
\end{tabular}

\section{Discussion}

The present work studied hydrogen donation and transfer pathways by DFT theory using a model compound. In the DCL process, the concerted mechanism was the dominant hydrogen donation mechanism; however, the possibility of donating a hydrogen atom through the stepwise mechanism increased as the temperature increased. For tetralin, two $\alpha-\mathrm{H}$ atoms $\left(\mathrm{C}_{1}-\mathrm{H}\right.$ and $\left.\mathrm{C}_{4}-\mathrm{H}\right)$ had the highest possibility to be donated first with the lowest reaction barrier. Tetralyl, a kind of radical, had difficulty capturing a hydrogen atom from hydrogen gas without the aid of a catalyst. The sequence of tetralin donating hydrogen atoms was $\mathrm{C}_{1}-\mathrm{H}>\mathrm{C}_{4}-\mathrm{H}>\mathrm{C}_{2}-\mathrm{H}>\mathrm{C}_{3}-\mathrm{H}$. Compared to the reaction of tetralin with methyl, it was harder for tetralin to donate its first hydrogen atom to benzyl radicals, while it was relatively easy for tetralin to donate its second and third hydrogen atoms to benzyls radicals. Therefore, it can be reasonably inferred that it is easier for coal radicals to capture hydrogen atoms from $\mathrm{H}$-donor solvents than for coal radicals to obtain hydrogen atoms from hydrogen gas without the aid of a catalyst.

\section{Materials and Methods}

All calculations were performed using the Gaussian 09 program package (Gaussian 09, Revision, A. 02, Gaussian, Inc., Wallingford, CT, USA) [32]. The geometry of each compound and the radical structure were optimized using the DFT method with B3LYP/6-311 + G(d,p) basis set [33-35]. All Cartesian coordinates of the intervening species are given in the Supplementary Materials. Except for the stable structures without single electron spin, all other optimized structures were calculated using the unrestricted wave function. Frequency calculations were carried out to check whether each stationary was an intermediate (no negative frequency) or a transition state (exactly only one negative frequency, see Supplementary Materials). Furthermore, for some suspicious transition states, the intrinsic reaction coordinate (IRC) calculations [36] were performed for both forward and reverse directions to confirm that the optimized transition states correctly connected the relevant reactants and products. The barrier (Ea) and reaction energy (DG) were calculated according to $\mathrm{Ea}=\mathrm{E}_{\mathrm{TS}}-\mathrm{E}_{\mathrm{IS}}$ and $\mathrm{DG}=\mathrm{E}_{\mathrm{FS}}-\mathrm{E}_{\mathrm{IS}}$, where $\mathrm{E}_{\mathrm{IS}}, \mathrm{E}_{\mathrm{FS}}$, and $\mathrm{E}_{\mathrm{TS}}$ are the sum of electronic and thermal free energies of the corresponding initial state (IS), final state (FS), and transition state (TS), respectively. Similarly, the bond dissociation energies (BDE) were calculated according to $\mathrm{BDE}=\mathrm{E}_{\mathrm{FS}}-\mathrm{E}_{\mathrm{IS}}$, where $\mathrm{E}_{\mathrm{IS}}$ and $\mathrm{E}_{\mathrm{FS}}$ are also the free energies of the corresponding initial state (IS) and final state (FS), respectively.

In the calculations, the parameter of SCRF $=($ Solvent $=$ Tetralin, $\mathrm{PCM})$ was set for the liquid phase simulations, which represented the effect of the solvent, while the default value of SCRF was used in the gas phase simulations. 
Supplementary Materials: The following are available online at http:/ / www.mdpi.com/2073-4344/8/12/648/s1, Appendix S1: The Cartesian coordinates of intervening species (reactants, transition states, and products) in the energy profiles.

Author Contributions: Conceptualization, H.H.; Formal analysis, L.G. and R.S.; Investigation, H.H. and T.C.; Project administration, R.G.; Software, T.C.; Supervision, R.G.; Visualization, L.G. and R.S.; Writing-Original Draft, H.H.; Writing-Review \& Editing, R.G.

Funding: This research was funded by the Program of Higher-level Talents of IMU (21300-5185111) and the Program of Higher-level Talents of IMU (21300-5185109).

Acknowledgments: The authors are grateful for advice from Jianli Yang. We also acknowledge Synfuels China, Co. Ltd. for the free use of their Super-Server for the DFT calculations.

Conflicts of Interest: The authors declare no conflict of interest.

\section{References}

1. Vasireddy, S.; Morreale, B.; Cugini, A.; Song, C.; Spivey, J.J. Clean liquid fuels from direct coal liquefaction: Chemistry, catalysis, technological status and challenges. Energy Environ. Sci. 2011, 4, 311-345. [CrossRef]

2. Liu, Z.; Shi, S.; Li, Y. Coal liquefaction technologies-Development in China and challenges in chemical reaction engineering. Chem. Eng. Sci. 2010, 65, 12-17. [CrossRef]

3. Shui, H.; Cai, Z.; Xu, C. Recent advances in direct coal liquefaction. Energies 2010, 3, 155-170. [CrossRef]

4. Gao, S.; Zhang, D.; Li, K. Effect of recycle solvent hydrotreatment on oil yield of direct coal liquefaction. Energies 2015, 8, 6795-6805. [CrossRef]

5. Ouchi, K.; Makabe, M. Hydrogen transfer in the hydrogenation of model compounds. Fuel 1988, 67, 1536-1541. [CrossRef]

6. Kabe, T.; Nitoh, O.; Funatsu, E.; Yamamoto, K. Studies on hydrogen transfer mechanisms in coal liquefaction by means of ${ }^{3} \mathrm{H}$ and ${ }^{14} \mathrm{C}$ trancer techniques. Fuel Process. Technol. 1986, 14, 91-101. [CrossRef]

7. Bate, K.; Harrison, G. Fate of hydrogen-donor molecules in two-stage liquefaction using model solvents. Fuel 1992, 71, 289-305. [CrossRef]

8. Vernon, L.W. Free radical chemistry of coal liquefaction: Role of molecular hydrogen. Fuel 1980, 59, $102-106$. [CrossRef]

9. Skowronski, R.P.; Ratto, J.J.; Goldberg, I.B.; Heredy, L.A. Hydrogen incorporation during coal liquefaction. Fuel 1984, 63, 440-448. [CrossRef]

10. Robinson, K.K. Reaction engineering of direct coal liquefaction. Energies 2009, 2, 976-1006. [CrossRef]

11. Miller, R.L.; Silver, H.F. Solvent Effects on the Hydro-liquefaction of Wyodak Coal. Energy Sources 1980, 5, 211-222. [CrossRef]

12. Franck, H.G.; Stadelhofer, J.W.; Biermann, D. Solubilization of bituminous coal in aromatic and hydroaromatic solvents. Fuel 1983, 62, 78-80. [CrossRef]

13. Joseph, J.T. Liquefaction behaviour of solvent-swollen coals. Fuel 1991, 70, 139-144. [CrossRef]

14. Nishioka, M. Role of solvation for coal swelling in slurry. Energy Fuels 2002, 16, 1109-1115. [CrossRef]

15. Ritger, P.L.; Peppas, N.A. Transport of penetrants in the macromolecular structure of coals 4 . Models for analysis of dynamic penetrant transport. Fuel 1987, 66, 815-826. [CrossRef]

16. Malhotra, R.; McMillen, D.F. Relevance of cleavage of strong bonds in coal liquefaction. Energy Fuels 1993, 7, 227-233. [CrossRef]

17. Autrey, T.; Alborn, E.A.; Franz, J.A.; Camaioni, D.M. Solvent-induced scission of diarylmethanes in dihydroarene donor solvents. An experimental and mechanistic modeling study of hydrogen-transfer pathways. Energy Fuels 1995, 9, 420-428. [CrossRef]

18. McMillen, D.F.; Malhotra, R.; Chang, S.J.; Ogier, W.C.; Nigenda, S.E.; Flemingt, R.H. Mechanisms of hydrogen transfer and bond scission of strongly bonded coal structures in donor-solvent systems. Fuel 1987, 66, 1611-1620. [CrossRef]

19. Malhotra, R.; McMillen, D.F. A mechanistic numerical model for coal liquefaction involving hydrogenolysis of strong bonds. Rationlization of interactive effect of solvent aromaticity and hydrogen pressure. Energy Fuels 1990, 4, 184-193. [CrossRef]

20. Wei, X.; Ogata, E.; Zong, Z.; Zhou, S.; Qin, Z.; Liu, J.; Shen, K.; Li, H. Advances in the study of hydrogen transfer to model compounds for coal liquefaction. Fuel Process. Technol. 2000, 62, 103-107. [CrossRef] 
21. Li, X.; Hu, S.; Jin, L.; Hu, H. Role of iron-based catalyst and hydrogen transfer in direct coal liquefaction. Energy Fuels 2008, 22, 1126-1129. [CrossRef]

22. Mochida, I.; Iwamoto, K.; Tahara, T.; Korai, Y.; Fujitsu, H.; Takeshita, K. Liquefaction of subbituminous coals under apparently non-hydrogenative conditions. Fuel 1982, 61, 603-609. [CrossRef]

23. Kuhlmann, E.J.; Jung, D.Y.; Guptill, R.P.; Dyke, C.A.; Zang, H.K. Coal liquefaction using a hydrogenated creosote oil solvent: H-atom transfer from hydrogen donor components in the solvent. Fuel 1985, 64, 1552-1557. [CrossRef]

24. Godo, M.; Saito, M.; Sasahara, J.; Ishihara, A.; Kabe, T. Elucidation of coal liquefaction mechanism using a tritium tracer method. Effect of $\mathrm{H}_{2} \mathrm{~S}$ and $\mathrm{H}_{2} \mathrm{O}$ on hydrogen exchange reaction of tetralin with tritiated molecular hydrogen. Energy Fuels 1997, 11, 470-476. [CrossRef]

25. Khorasheh, F.; Gray, M.R. High-pressure thermal cracking of n-hexadecane in tetralin. Energy Fuels 1993, 7, 960-967. [CrossRef]

26. Khorasheh, F.; Gray, M.R. High-pressure thermal cracking of n-hexadecane in aromatic solvents. Ind. Eng. Chem. Res. 1993, 32, 1864-1876. [CrossRef]

27. Johnson, E.R.; Clarkin, O.J.; DiLabio, G.A. Density Functional Theory Based Model Calculations for Accurate Bond Dissociation Enthalpies. 3. A Single Approach for $X-H, X-X$, and $X-Y(X, Y=C, N, O, S$, Halogen $)$ Bonds. J. Phys. Chem. A 2003, 107, 9953-9963. [CrossRef]

28. Hou, P.; Zhou, Y.; Guo, W.; Ren, P.; Guo, Q.; Xiang, H.; Yang, Y. Rational Design of Hydrogen-Donor Solvents for Direct Coal Liquefaction. Energy Fuel 2018, 32, 4715-4723. [CrossRef]

29. Curtis, C.W.; Guin, J.A.; Hale, M.A.; Smith, N.L. Contribution of transferable hydrogen to coal conversion. Fuel 1985, 64, 461-469. [CrossRef]

30. Kamiya, Y.; Futamura, S.; Mizuki, T.; Kajioka, M.; Koshi, K. Solvent effect on coal liquefaction. Fuel Process. Technol. 1986, 14, 79-90. [CrossRef]

31. Shi, L.; Liu, Q.; Guo, X.; Wu, W.; Liu, Z. Pyrolysis behavior and bonding information of coal-a TGA study. Fuel Process. Technol. 2013, 108, 125-132. [CrossRef]

32. Frisch, M.; Trucks, G.W.; Schlegel, H.B. Gaussian 09, Revision, A. 02, Gaussian, Inc.: Wallingford, CT, USA, 2009; p. 200.

33. Becke, A.D. Density-functional thermochemistry. III. The role of exact exchange. J. Chem. Phys. 1993, 98, 5648-5652. [CrossRef]

34. Becke, A.D. Density-functional exchange-energy approximation with correct asymptotic behavior. Phys. Rev. A 1988, 38, 3098-3100. [CrossRef]

35. Lee, C.; Yang, W.; Parr, R.G. Development of the Colle-Salvetti correlation-energy formula into a functional of the electron density. Phys. Rev. B 1988, 37, 785-789. [CrossRef]

36. Gonzalez, C.; Schlegel, H.B. An improved algorithm for reaction path following. J. Chem. Phys. 1989, 90, 2154-2161. [CrossRef]

(C) 2018 by the authors. Licensee MDPI, Basel, Switzerland. This article is an open access article distributed under the terms and conditions of the Creative Commons Attribution (CC BY) license (http://creativecommons.org/licenses/by/4.0/). 